supported by the Air Research and Development Command, United States Air Force.

S. Aftergut

G. P. Brown

General Engineering Laboratory,

General Electric Co.

Schenectady, New York.

${ }^{t}$ Lyons, L. E., and Morris, G. C., J. Chem. Soc, 3648 (1957).

${ }^{2}$ Aftergut, S., and Brown, G. P., Nature, 189, 827 (1961).

${ }^{3}$ Eley, D. D. Inokuchi, H., and Willis, M. R., Disc. Farad. Soc., No. $28,54(1959)$

\section{Formation of Boron Nitride in Diborane-Hydrazine Flames}

Although reactions of metals with nitrogen or nitrogen compounds leading to nitrides are well known $^{1}$, the literature on eombustion is devoid of descriptions of flames from the reaction between boron hydrides and nitrogen hydrides (ammonia, hydrazine). This communication reports a steady-state flame of diborane and hydrazine, in which the reaction products consist principally of boron nitride and hydrogen, according to the reaction $\mathrm{B}_{2} \mathrm{H}_{6}+\mathrm{N}_{2} \mathrm{H}_{4} \rightarrow$ $2 \mathrm{BN}+5 \mathrm{H}$

Even though the value of the heat of formation of boron nitride is not fully established (27-32 kcal. $/ \mathrm{mol}$. in ref. $2,60.2 \mathrm{kcal} . / \mathrm{mol}$. in ref. 3) the above reaction is sufficiently exothermic for it to proceed without difficulty. Examination of this system is complicated, however, by a rapid gas-phase reaction of boron hydrides with ammonia, hydrazine or amines, leading to a variety of solid 'adducts'4, which prevents premixing of the components prior to combustion. To overcome this problem a novel burner was constructed, consisting of a closely spaced array of capillaries (Fig. 1) by means of which a 'multi-diffusion' flame is established in a laminar mixing zone. This type of burner is of general utility for combustion studies in which premixing of components is impractical or impossible, but where it is desirable to investigate the reaction products from flames approaching the premixed state.
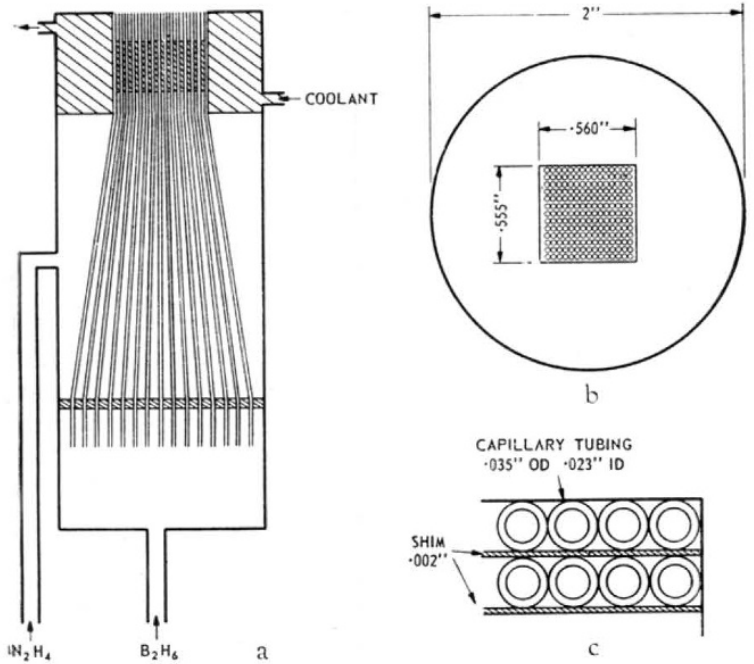

Fig. 1. Schematic diagram of capillary multidiffusion burner. $a$, Cross-section, showing arrangement of separate feeds for two incompatible gaseous components; $b$, top view; $c$, details of capillary assembly. Symmetrical assembly of tubes is essential to provide uniform gas flow at top of the burner. Metal shims are used as spacers between rows of capillaries

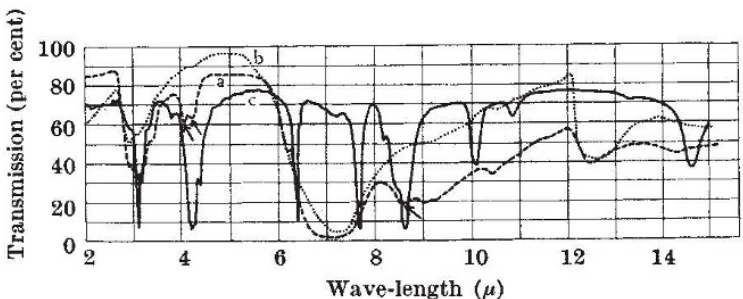

Fig. 2. Infra-red spectra of: $a$, solid reaction products from the $\mathrm{B}_{2} \mathrm{H}_{6}-\mathrm{N}_{2} \mathrm{H}_{4}$ flame; $b$, boron nitride; $c$, diborane-hydrazine duct (Callery Chemical Co.). The arrowed absorption bands in $a$ are due to the presence of small amounts of adduct

To achieve the boron nitride reaction a flat hydrazine decomposition flame is established first (requiring thermostatting the burner and fuel-feed above $100^{\circ} \mathrm{C}$. to obtain an adequately high hydrazine vapour pressure). Subsequent addition of diborane through the separate feed system leads to a flame with copious evolution of solid reaction products consisting predominantly of boron nitride. As shown by infrared (Fig. 2) and chemical analyses only small amounts of bound hydrogen appear as impurity in the solid.

By measurement of the flame temperature and the composition of the products of combustion an independent value for the heat of formation of boron nitride is being obtained.

This work was carried out under contract NOrd 7386 of the U.S. Navy.

W. G. BerL

W. E. WiLson

Applied Physics Laboratory,

The Johns Hopkins University, Silver Spring, Maryland.

${ }^{1}$ Sidgwick, N. V., The Chemical Elements and Their Compounds, 1. 663 (Oxford Üniv. Press, 1950).

${ }^{2}$ Gmelins Handbuch der Anorganischen Chemie, eighth ed., Boron Supp., 159 (Verlag Chemie, Weinheim, 1954).

salchenko G. L et al. Proc. Acad. Sci. U.S.S.R. (Chem. Section), 127,635 (1959) (English translation, Consultants Bureau, Inc.) " Parry, D. W., et al., J. Amer. Chem. Soc., 80, 4 (1958). Emeléus, H. J., and Stone, F. G. A., J. Chem. Soc., 840 (1951).

\section{Determination by Mass Spectrometry of the} Structure of Proline Derivatives from Apples

Hulme $^{1}$ and Urbach ${ }^{2}$ independently isolated a new amino-acid from apples, and the isomeric structures $\mathrm{I}^{2}$ and $\mathrm{II}^{1,3}$ were proposed for these substances on the basis of elemental analysis, colour reactions and chromatographic properties ${ }^{1-3}$. The infra-red spectra of these compounds proved to be superimposable, and this indicated that the compounds were identical, but it did not permit a decision between the alternative structures ${ }^{3}$.<smiles>CC1(CO)C[C@](CO)(C(=O)O)CN1</smiles>

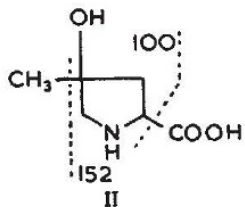<smiles>O=C(O)[C@H]1C[C@@H](CO)CN1</smiles><smiles>O=C(O)C1NCCC1CO</smiles>

10

III 